\title{
In vitro Activities of Various Antimicrobials against Brucella melitensis Strains in the Aegean Region in Turkey
}

\author{
Tansu Yamazhan $^{\mathrm{a}}$ Şöhret Aydemir ${ }^{\mathrm{b}}$ Alper Tünger ${ }^{\mathrm{b}}$ Demir Serter ${ }^{\mathrm{a}}$ \\ Deniz Gökengin ${ }^{\mathrm{a}}$
}

Departments of ${ }^{a}$ Infectious Diseases and Clinical Microbiology, and ${ }^{\mathrm{b}}$ Microbiology and Clinical Microbiology,

Faculty of Medicine, Ege University, Izmir, Turkey

\section{Key Words}

Agar dilution method - Antibiotic susceptibility · Brucella melitensis

\begin{abstract}
Objective: To study in vitro activities of three quinolones (ciprofloxacin, levofloxacin, moxifloxacin), four macrolides (erythromycin, dirithromycin, azithromycin, clarithromycin) and doxycycline against 44 clinical isolates of Brucella melitensis. Materials and Methods: Fortyfour $B$. melitensis strains were isolated from blood cultures of adult patients with acute brucellosis who were hospitalized in the clinical ward of the Department of Clinical Microbiology and Infectious Diseases. The minimum inhibitory concentrations (MICs) of the tested antimicrobials were measured by the agar dilution method. $\mathrm{MIC}_{90}$ and $\mathrm{MIC}_{50}$ values were defined as the lowest concentration of the antibiotic at which 90 and $50 \%$ of the isolates were inhibited, respectively. Results: Doxycycline $\left(\mathrm{MIC}_{50}: 0.25 \mu \mathrm{g} / \mathrm{ml}, \mathrm{MIC}_{90}: 0.50 \mu \mathrm{g} / \mathrm{ml}\right.$ ) had the lowest MIC in vitro against the $B$. melitensis strains. Among the quinolones, ciprofloxacin and levofloxacin had similar activities $\left(\mathrm{MIC}_{50}: 0.5 \mu \mathrm{g} / \mathrm{ml}, \mathrm{MIC}_{90}: 2 \mu \mathrm{g} / \mathrm{ml}\right.$ ), whereas
\end{abstract}

MIC of moxifloxacin $\left(\mathrm{MIC}_{50}: 1 \mu \mathrm{g} / \mathrm{ml}, \mathrm{MIC}_{90}: 8 \mu \mathrm{g} / \mathrm{ml}\right.$ ) was higher than both antibiotics in this group. Clarithromycin and azithromycin were the most active macrolides $\left(\mathrm{MIC}_{50}: 8 \mu \mathrm{g} / \mathrm{ml}\right.$ and $\mathrm{MIC}_{90}: 32 \mu \mathrm{g} / \mathrm{ml}$ ), followed by erythromycin $\left(\mathrm{MIC}_{50}: 16 \mu \mathrm{g} / \mathrm{ml}, \mathrm{MIC}_{90}: 32 \mu \mathrm{g} / \mathrm{ml}\right.$ ) and dirithromycin ( $\mathrm{MIC}_{50}: 64 \mu \mathrm{g} / \mathrm{ml}$ and $\left.\mathrm{MIC}_{90}: 64 \mu \mathrm{g} / \mathrm{ml}\right)$. Conclusion: The results indicate that the conventional agent doxycycline is more active than quinolones and macrolides against the $B$. melitensis in vitro.

Copyright $@ 2005$ S. Karger AG, Base

\section{Introduction}

Human brucellosis in Turkey is a serious public health problem in countries where Brucella melitensis is prevalent in sheep and other domestic animals, and it is one of the most common infectious conditions contracted by man [1]. Brucellosis is a long-term disease with frequent relapses. The major antimicrobials used in the treatment of brucellosis worldwide are doxycycline, rifampicin, streptomycin and trimethoprim-sulfamethoxazole [2]. Recently fluoroquinolones and newer macrolides have been used in combination with these major microbials [3,

\section{KARGER}

Fax +4161306 1234 E-Mail karger@karger.ch www.karger.com
Tansu Yamazhan, MD

Department of Infectious Diseases and Clinical Microbiology

Faculty of Medicine, Ege University

TR-35100 Bornova, Izmir (Turkey)

Tel. +90 232 3903305, Fax +90 232 3734538, E-Mail tyamazhan@med.ege.edu.tr 
4]. Despite having alternative therapies, treatment of brucellosis is still problematic due to factors such as side effects of some antibiotics, poor compliance of patients, and the high relapse rate with some of the combination regimens [5].

The purpose of this study was to compare the in vitro susceptibility of clinical isolates of $B$. melitensis to three quinolones (ciprofloxacin, levofloxacin, moxifloxacin), four macrolides (erythromycin, dirithromycin, azithromycin, clarithromycin) and the conventional agent doxycycline.

\section{Materials and Methods}

The study was performed on $44 \mathrm{~B}$. melitensis strains, which were isolated from blood cultures of hospitalized adult patients with acute brucellosis between 1998 and 2003. B. melitensis strains were identified by conventional methods (gram staining, no $\mathrm{CO}_{2}$ requirement, production of $\mathrm{H}_{2} \mathrm{~S}$, and other biochemical properties). Stocked strains were stored in protect bacterial preservers (Technical Service Consultant Ltd., Lancashire, England) at $-80^{\circ} \mathrm{C}$ and were subcultured twice a week prior to the study.

The antibiotics were provided by the following suppliers in powder form: erythromycin (Sigma, Istanbul, Turkey); dirithromycin (Abdi İbrahim İlaç Sanayi ve Ticaret AȘ, Istanbul, Turkey); azithromycin and clarithromycin (Adilna Sanovel İlaç Sanayii, Istanbul, Turkey); ciprofloxacin and moxifloxacin (Bayer, Istanbul, Turkey); levofloxacin and doxycycline (Fako İlaçları AŞ, Istanbul, Turkey).

The agar dilution method as previously described [6] was used to determine the minimum inhibitory concentrations (MICs) of the antimicrobial agents. Mueller-Hinton agar (Oxoid Ltd., Basingstoke, Hampshire, England) supplemented with 1\% hemoglobin (bioMérieux, Lyon, France) and 1\% PoliVitex (bioMérieux) was used as the culture medium. The stock solutions of the antibiotics were prepared in $100 \mathrm{ml}$ of sterile distilled water and stored frozen in small volumes, in sterile polypropylene vials at $-70^{\circ} \mathrm{C}$. Serial twofold dilutions of the antimicrobial agents were prepared in Mueller-Hinton broth supplemented with $1 \%$ PoliVitex. The concentration range was $0.125-64 \mu \mathrm{g} / \mathrm{ml}$ for the macrolides, and $0.03-$ $16 \mu \mathrm{g} / \mathrm{ml}$ for the quinolones and doxycycline.

The bacterial inoculum was prepared by suspending smooth B. melitensis strains cultivated in Brucella agar (Difco), in brainheart infusion broth. Following $48 \mathrm{~h}$ incubation, the suspensions were adjusted to $0.5 \mathrm{McF}$ arland turbidity to yield a final inoculum of $10^{5}-10^{6} \mathrm{cfu} / \mathrm{ml}$. The inoculations were made by a multipoint inoculator. Plates were incubated at $35^{\circ} \mathrm{C}$ in ambient conditions. The results were evaluated after $48 \mathrm{~h}$. MIC values were defined as the lowest concentration of the antibiotic that completely inhibited growth. $\mathrm{MIC}_{90}$ and $\mathrm{MIC}_{50}$ values were defined as the lowest concentration of the antibiotic at which 90 and $50 \%$ of the isolates were inhibited, respectively. All measurements were performed in duplicate. Escherichia coli ATCC 25922 and Staphylococcus aureus ATCC 29213 and plates of Mueller-Hinton agar without antibiotics were used as controls.
Table 1. Susceptibility of $44 \mathrm{~B}$. melitensis isolates to several antibiotics

\begin{tabular}{lccc}
\hline Antimicrobial agents & \multicolumn{2}{l}{$\mathrm{MIC}, \mu \mathrm{g} / \mathrm{ml}^{1}$} & \\
\cline { 2 - 4 } & range & $50 \%$ & $90 \%$ \\
\hline Ciprofloxacin & $0.25-16$ & 0.5 & 2 \\
Levofloxacin & $0.25-16$ & 0.5 & 2 \\
Moxifloxacin & $0.5-16$ & 1 & 8 \\
Erythromycin & $2-64$ & 16 & 32 \\
Azithromycin & $1-32$ & 8 & 32 \\
Clarithromycin & $0.125-32$ & 8 & 32 \\
Dirithromycin & $8-64$ & 64 & 64 \\
Doxycycline & $\leq 0.03-1$ & 0.25 & 0.50 \\
\hline
\end{tabular}

${ }^{1} \mathrm{MIC}_{50}$ and $\mathrm{MIC}_{90}$, at which 50 and $90 \%$ of the isolates are inhibited, respectively.

\section{Results}

The MIC values of the antimicrobial agents studied by the agar dilution method are listed in table 1. Doxycycline had the lowest MIC in vitro against the $B$. melitensis strains. Among the quinolones, ciprofloxacin and levofloxacin had similar activities $\left(\mathrm{MIC}_{50}: 0.5 \mu \mathrm{g} / \mathrm{ml} ; \mathrm{MIC}_{90}\right.$ : $2 \mu \mathrm{g} / \mathrm{ml}$ ), whereas the MIC of moxifloxacin $\left(\mathrm{MIC}_{50}\right.$ : $1 \mu \mathrm{g} / \mathrm{ml} ; \mathrm{MIC}_{90}: 8 \mu \mathrm{g} / \mathrm{ml}$ ) was higher than that of both antibiotics in this group. Among the macrolides, clarithromycin and azithromycin $\left(\mathrm{MIC}_{50}: 8 \mu \mathrm{g} / \mathrm{ml}\right.$ and $\mathrm{MIC}_{90}$ : $32 \mu \mathrm{g} / \mathrm{ml}$ ) were the most active macrolides, followed by erythromycin $\left(\mathrm{MIC}_{50}: 16 \mu \mathrm{g} / \mathrm{ml} ; \mathrm{MIC}_{90}: 32 \mu \mathrm{g} / \mathrm{ml}\right)$ and dirithromycin $\left(\mathrm{MIC}_{50}\right.$ and $\left.\mathrm{MIC}_{90}: 64 \mu \mathrm{g} / \mathrm{ml}\right)$.

\section{Discussion}

When compared with previous studies, the strains examined in this study had higher MIC values for all drugs except doxycycline [7,8]. This result may be due to the regional differences in the resistance rates of Brucella strains in Turkey, where brucellosis is an endemic disease. The considerably high MICs for macrolides are of specific importance. Although it is forbidden by the Ministry of Agriculture, some antibiotics (naracin, avoparcin, erythromycin and other macrolides) are found in animal feed [personal commun., Prof. Figen Kırkpınar, Ege University, Agriculture Faculty, Department of Animal Science]. This may explain the high resistance rates to macrolides among $B$. melitensis in our region. Inappropriate quinolone and macrolide usage is somewhat higher than 
that of tetracyclines in Turkey, hence the fact that all the strains were clinical isolates may also contribute to the higher macrolide and quinolone resistance [9].

The combination of doxycycline and rifampin is currently recommended by the World Health Organization for patients with acute brucellosis [10], but the limited number of effective antibiotics, adverse effects, therapeutic failures and the necessity to use antimicrobials for long periods of time in patients with localized brucellosis have led to a search for new drugs to combat the disease. Quinolones are among the leading drugs for future potential therapeutic options. Quinolones are widely used in the treatment of brucellosis in our country because they possess excellent bioavailability after oral intake and achieve high concentrations in tissues, macrophages and leukocytes [11]. However, their reduced activity in acidic $\mathrm{pH}$, the development of resistance in B. melitensis during ciprofloxacin therapy and cross-resistance to other fluoroquinolones made them unfavorable in brucellosis therapy in a short time [12, 13].

In the present study, while the $\mathrm{MIC}_{50}$ and $\mathrm{MIC}_{90}$ values for ciprofloxacin and levofloxacin were similar (0.5 and $2 \mu \mathrm{g} / \mathrm{ml}$, respectively), the $\mathrm{MIC}_{90}$ value for moxifloxacin $(8 \mu \mathrm{g} / \mathrm{ml})$ was twofold higher than those of the other quinolones, and these were significantly higher than previously reported [8, 14]. Martin et al. [14] reported $\mathrm{MIC}_{90} 0.06 \mu \mathrm{g} / \mathrm{ml}$ for sitafloxacin against $B$. melitensis strains in vitro.

Although the value of $\mathrm{MIC}_{90}$ for doxycycline $(0.5 \mu \mathrm{g} /$ $\mathrm{ml})$ and ciprofloxacin $(2 \mu \mathrm{g} / \mathrm{ml})$ in this study is higher than (doxycycline: $0.064 \mu \mathrm{g} / \mathrm{ml}$ and ceftriaxone: $0.25 \mu \mathrm{g} /$ $\mathrm{ml}$ ) that reported by Bodur et al. [8], the magnitude of the values is approximately the same (fourfold).

Macrolides are generally perceived as safe and effective antibiotics, with good activity against Brucella spp. However, the MIC values of the isolates in this study were higher compared to those previously reported [15-17]. Of the four macrolides tested in this study, dirithromycin was the least active agent $(64 \mu \mathrm{g} / \mathrm{ml})$, thereby supporting our previous in vivo findings in a murine brucellosis mod$\mathrm{el}$, in which dirithromycin had the lowest cure rate alone or in combination with rifampicin [18].

Doxycycline had the lowest $\mathrm{MIC}_{90}$ value in our study. This finding is consistent with data reported in previous studies $[8,13,19,20]$ involving the cyclines.

\section{Conclusion}

The antimicrobial susceptibility of $B$. melitensis isolates in our region showed that the conventional agent doxycycline is more active than quinolones and macrolides. Our findings further indicate that there is an increasing resistance among $B$. melitensis strains against macrolides and quinolones.

\section{Acknowledgments}

The authors wish to thank to Sigma Istanbul, Turkey, AdilnaSanovel İlaçları AŞ, Fako İlaçları, Bayer Istanbul, Turkey and the Abdi İbrahim İlaç Sanayii Ticaret AŞ for providing the powder forms of the drugs.

\section{References}

1 Report of the Turkish Ministry of Health, Division of Communicable Diseases, May 2001.

2 Doganay M, Aygen B: Human brucellosis: an overview. Int J Infect Dis 2003;7:173-182.

3 Lang R, Rubinstein E: Quinolones for the treatment of brucellosis. J Antimicrob Chemother 1992;29:357-359.

-4 Akova M, Uzun Ö, Akalın E, Hayran M, Ünal S, Gür D: Quinolones in treatment of human brucellosis: comparative trial of ofloxacin-rifampin versus doxycycline-rifampin. Antimicrob Agents Chemother 1993;37:1831-1834.

$\checkmark 5$ Accocella GA, Bertrand J, Beytount J, Durrande JA, Garcia-Rodriguez J, Kosmidis M, Micoud M, Rey M, Rodriguez Z, Roux J, Stahl $\mathrm{P}$ : Comparison of the three difference regimens in the treatment of acute brucellosis: a multicenter multinational study. J Antimicrob Chemother 1990;23:433-439.
6 Bosch J, Linares J, Lopez de Goicoechae MJ, Ariza J, Cisnal MC, Martin R: In-vitro activity of ciprofloxacin, ceftriaxone and five other antimicrobial agents against 95 strains of Brucella melitensis. J Antimicrob Chemother 1986; 17:459-461.

7 Kocagöz S, Akova M, Altun B, Gür D, Hasçelik G: In vitro activities of new quinolones against Brucella melitensis isolated in a tertiary-care hospital in Turkey. Clin Microbiol Infect 2002;8:240-242.

8 Bodur H, Balaban N, Aksaray S, et al: Biotypes and antimicrobial susceptibilities of Brucella isolates. Scand J Infect Dis 2003;35:337-338.

-9 Tunger O, Dinc G, Ozbakkaloglu B, Atman UC, Algun U: Evaluation of rational antibiotic use. Int J Antimicrob Agents 2000;15:131-135.
10 Joint FAO/WHO expert committee on brucellosis. World Health Organ Tech Rep Ser 1986; 740.

11 Easmon CS, Crane JP, Blowers A: Effect of ciprofloxacin on intracellular organism in vitro and in vivo studies. $\mathbf{J}$ Antimicrob Chemother 1986; 18:43-48.

12 al-Sibai MB, Halim MA, el-Shaker MM, Khan BA, Quadri SM: Efficacy of ciprofloxacin for treatment of Brucella melitensis infections. Antimicrob Agents Chemother 1992;36:150152.

13 Akalın HE, Ünal S, Gür D, Baykal M: Ofloxacin in the treatment of brucellosis. Proc 3rd Int Symp on Quinolones, Vancouver, Canada. Eur J Clin Microbiol Infect Dis 1990;(special issue):326-328. 
14 Martin IT, Sanchez EG, Martinez IM, Fresnadillo MJ, Sanchez EG, Rodriguez AG: In vitro activities of six new fluoroquinolones against Brucella melitensis. Antimicrob Agents Chemother 1999;43:194-195.

15 Garcia Rodriguez JA, Munoz Bellino JL, Fresnadillo MJ, Trujillano I: In vitro activities of new macrolides and rifapentine against $\mathrm{Bru}$ cella spp. Antimicrob Agents Chemother 1993; 37:911-913.
16 Landinez R, Linares J, Loza E, Martinez-Beltran J, Martin R, Baquero F: In vitro activities of azithromycin and tetracycline against 358 clinical isolates of Brucella melitensis. Eur $\mathbf{J}$ Clin Microbiol Infect Dis 1992;11:265-267.

17 Qadri HSM, Halim MA, Ueno Y, Abumustafa FM, Postle AG: Antibacterial activity of azithromycin against Brucella melitensis. Chemotherapy 1995;41:253-256.

18 Arda B, Tunçel M, Yamazhan T, Gökengin D, Gürel Ö: Efficacy of oral levofloxacin and dirithromycin alone and in combination with rifampicin in the treatment of experimental murine Brucella abortus infection. Int J Antimicrob Agents 2004;23:204-207.
19 Dhar R, Araj GF, Kisswani SM, Chugh TD: In vitro activity of conventional and newer antimicrobial agents in Brucella melitensis clinical isolates from Kuwait. Med Principles Pract 1990;2:110-117.

20 Rubinstein E, Lang R, Shasha B, Hagar B, Diamanstein L, Joseph G, Anderson M, Harrison $\mathrm{K}$ : In vitro susceptibility of Brucella melitensis to antibiotics. Antimicrob Agents Chemother 1991;35:1925-1927. 